\title{
ARTÍCULOS
}

Sometido 24.09.2013. Aprobado 03.04.2014

Evaluado por el sistema double blind review. Editor Científico: Diogo Henrique Helal

DOI: http://dx.doi.org/10.1590/So034-759020160109

\section{GESTIÓN HUMANA DE ORIENTACIÓN ANALIITICA: UN CAMINO PARA LA RESPONSABILIZACIÓN}

\author{
Gestão humana de orientação analítica: Um caminho para a responsabilização \\ Analytical orientation human management: $A$ path to responsibilization
}

\begin{abstract}
RESUMEN
El presente artículo propone un enfoque de la gestión humana que privilegia espacios conversacionales en la organización. Consideramos que la verbalización tiene como efectos la simbolización, socialización y responsabilización en los sujetos individuales, grupales y colectivos. Dedicamos especial interés a la responsabilización, resaltando que la participación a través de la palabra genera compromiso, inclusión y sentido de pertenencia. En los casos estudiados, privilegiamos el método analítico entendido como método de análisis del discurso, el cual fundamenta la actitud del profesional que basa su quehacer en escuchar, analizar e intervenir. Los hallazgos de la investigación permiten plantear una vía para la responsabilidad empresarial.
\end{abstract}

PALABRAS CLAVE | Gestión humana, orientación analítica, verbalización, responsabilización, desarrollo humano.

\section{RESUMO}

Este artigo apresenta uma abordagem para a gestão de recursos humanos, em que a verbalização é favorecida na organização, a fim de criar espaços de conversação que facilitem a simbolização, a socialização e a responsabilização sobre os indivíduos, grupos e sobre a organização. Dedicamos especial atenção à responsabilização, com a realização dos resultados da pesquisa como uma forma de responsabilidade corporativa, enfatizando que a participação através da palavra gera engajamento, inclusão e um sentido de pertencimento nos indivíduos. Nos casos analisados, favorecemos o método analítico, compreendido como um método de análise do discurso, e como uma atitude profissional baseada no ouvir, analisar e intervir.

PALAVRAS-CHAVE / Gestão humana, orientação analítica, verbalização, responsabilização, desenvolvimento humano.

JUAN DAVID PEREZ PATINO

jperezp3@eafit.edu.co

Magister en Desarrollo Humano Organizacional por la Universidad

EAFIT Departamento de Organización y Gerencia-Medellín, Colombia

\section{ISABEL CRISTINA LOPERA ARBELAZ}

ilopera@eafit.edu.co

Profesora de la Universidad EAFIT

Departamento de Organización y

Gerencia-Medellín, Colombia

\section{ABSTRACT}

The present paper proposes an approach to human management that privileges conversational spaces in the organization through verbalization, which results in symbolization, socialization and responsibilization of individuals in the organization groups. Our special concern is responsibilization, emphasizing that participation through conversation generates commitment, inclusion and a sense of belonging in individuals. In the cases studied, we have privileged the analytical method, understood as the method of discourse analysis, which underlies the attitude of the professional who grounds his work on listening, analyzing and intervening. The research findings allow the set out of a path to corporate responsibility.

KEYWORDS / Human management, analytical orientation, verbalization, responsibilization, human development. 


\section{INTRODUCCIÓN Y COMPONENTE TEÓRICO}

El presente artículo, producto de la investigación clínica de las organizaciones: una propuesta analítica, es elaborado en el marco de la maestría en Desarrollo humano organizacional de la Universidad EAFIT.

El objetivo del artículo es presentar una orientación de la gestión humana que le apuesta al desarrollo humano en la organización. Partimos de la aplicación del método analítico en el quehacer profesional de aquellos que tienen bajo su responsabilidad la coordinación de sujetos individuales o grupales. A través de la aplicación de la escucha, el análisis y la intervención de los discursos, proponemos una alternativa para promover procesos de responsabilización en los individuos, los grupos y la organización.

Esta perspectiva analítica pretende trascender la lógica instrumental y operativa que ha caracterizado la gestión humana en las organizaciones, lo cual implica ir más allá de los subsistemas o procesos, fundamentado en la incorporación de una actitud que propende por la responsabilización del sujeto, permitiendo plantear una vía para la ética organizacional desde la mediación en las relaciones socio-laborales.

El artículo se inscribe en la perspectiva de la clínica de las organizaciones, que se fundamenta en la comprensión de las dinámicas organizacionales, la cual tiene como finalidad propiciar el cuidado (cura, en el sentido foucaultiano del término) de un sujeto (individual, grupal o colectivo). Esta perspectiva se enfoca en el estudio e intervención de situaciones concretas tomando cada caso como un caso único, el cual no es posible tratarlo bajo modelos estandarizados y estadísticos. El énfasis que se da en las particularidades del sujeto y su cuidado, orientan prácticas que propician la expresión, escucha y análisis de los discursos lo cual favorece el desarrollo humano (Manrique \& Ramírez, 2014; Manrique, Lopera, \& Pérez, 2014; Manrique, Lopera, Pérez, Ramírez, \& Henao, 2014). Esta propuesta de trabajo es coherente con la perspectiva de las clínicas del trabajo (conforme Aubert \& Gaulejac, 1993; Bendassolli, 2011; Bendassolli \& Soboll, 2011; Malvezzi, 2012a, 2012b; Rossi, Mendes, Siqueira, \& García, 2009).

El propósito de esta investigación fue formalizar la propuesta teórica de una gestión humana de orientación analítica, que privilegia la verbalización como camino a la responsabilización subjetiva, basados en una "contrastación dialéctica entre la teoría y la práctica” (Ramírez, 1991, p. 35). En un principio abordaremos los referentes conceptuales a partir de los cuales delimitamos la concepción de gestión humana, considerando aspectos generales sobre su entendimiento y el rol que ha ocupado en la organización. Posteriormente presentaremos el método analítico como análisis del discurso y una forma de proceder que fundamenta dicha gestión (Lopera, Ramírez, Zuluag, \& Ortiz, 2010b; Ramírez, 2012).

\section{Gestión humana}

Desde inicios del siglo XX las ciencias sociales y la administración han tejido una relación influenciada por la racionalidad técnicoeconómica, tratando de dar respuestas a los problemas de la productividad, la rentabilidad, la optimización y el control, es decir, el problema de la eficacia (Chanlat, 2002). En efecto, aunque han sido múltiples los discursos en los que se considera el factor humano como actor organizacional, estas concepciones siguen siendo reduccionistas, concibiéndolo como un homo economicus (Bermúdez, 2011; Friedmann, 1956; Morin, 2005), un hombre sin afectos, sin historia y sin cultura, suscribiéndolo en una lógica instrumental, la cual parte de la idea de que el mundo humano es un conjunto de procesos objetivables que se intentan conocer y controlar (Cuevas, 2009; March \& Simon, 1961; Saavedra, 2006). El énfasis puesto sobre la rapidez de ejecución en detrimento de otros elementos del desempeño y del rendimiento tales como la motivación, el reconocimiento y la satisfacción, tiene por efecto reducir los intercambios y las expresiones más elementales. Lo anterior se refleja en el incremento de las posibilidades de violentar las reglas del buen vivir y la cortesía, sin espacios de participación que indican la escasa consideración por las personas que se encuentran enfrente, siendo incluso denominadas como una nueva forma de esclavitud moderna (Chanlat \& Bédard, 1997; Crane, 2013).

Para algunos autores la gestión es una forma de regulación del comportamiento de una colectividad social que cuenta con recursos limitados, para el logro de unos objetivos compartidos (Romero, 1998). Esta concepción apela al control del comportamiento humano en pro del cumplimiento de unos propósitos económicos-productivos que, al ser alineados a las realidades organizacionales, justifican la necesidad de establecer prácticas y actividades que dinamicen las relaciones entre las personas, el trabajo y la organización misma. Tal sería la justificación de la gestión humana.

Tradicionalmente, la gestión humana ha sido considerada como el eslabón organizacional encargado de dinamizar los fenómenos socio-laborales entre los colaboradores y las empresas, por medio de actividades tales como el diseño de cargos, selección, evaluación del desempeño, administración de la compensación y capacitación, entre otras, orientando sus acciones en aspectos técnicos e instrumentales que responden a las necesidades de productividad y competitividad de las organizaciones (Bermúdez, 2010; García, 2009; Melián \& 
Verano, 2008). Desde esta perspectiva, se mira al hombre en la organización de manera puramente mecanicista, como un medio o una herramienta para fines productivos y que puede ser descartado en cualquier momento (Kliksberg, 1995; Saldarriaga, 2010).

Diferentes autores han entendido la gestión humana como un conjunto de políticas, prácticas y actividades que incluyen una serie de técnicas para reclutar, seleccionar, capacitar, compensar y evaluar, en aras del cumplimiento de los objetivos organizacionales, teniendo un efecto directo sobre el comportamiento, actitudes, satisfacción, integración, etc., de una persona o un grupo reducido de personas dentro de la organización (Alfalla-Luque, Marín-Garcia, \& Medina-López, 2012; Aragón et al., 2004; Dessler, 2001).

Desde la concepción del management, la visión de la gestión humana se considera reduccionista y centrada en las prácticas y sus resultados en la organización. No obstante, el campo del conocimiento ha evolucionado y la gestión humana se concibe como un fenómeno complejo influenciado por múltiples aspectos que inciden en su concepción, filosofía y prácticas. Aspectos tales como los factores sociales, políticos y económicos del momento histórico, la concepción dominante del ser humano, las formas de organización del trabajo, la normatividad que rige las relaciones laborales, el mercado laboral y los desarrollos teóricos existentes (Calderón, Álvarez, \& Naranjo, 2006; Calderón, Naranjo, \& Álvarez, 2007).

Ante la realidad del management pareciera que se estuviera perdiendo de vista la premisa de que el hombre necesita establecer un lazo social con la organización y la actividad que desempeña, demandando ser reconocido y valorado como un ser íntegro y no simplemente como un engranaje más en la productividad organizacional, tal como se concibe bajo una mirada funcionalista y positivista de la administración. Dichas apreciaciones van en la vía de los planteamientos realizados en la perspectiva humanista de las ciencias de la vida y la gestión, reconocida hoy en día como una disciplina científica en el interior del campo administrativo (Zapata, 1995). Esta perspectiva plantea el retorno a las dimensiones olvidadas como la naturaleza genérica y singular del ser humano; su carácter activo y reflexivo; el uso de la palabra, la vida afectiva; la producción simbólica, la concepción espacio temporal y la alteridad como proceso de construcción del individuo (Aktouf, 2000, 2009; Bédard, 2003, 2004; Chanlat \& Bédard, 1997). Esto se enmarca en el paradigma de los estudios organizacionales, el cual parte de una concepción comprensiva y descriptiva de las realidades particulares de la organización, resaltando la vivencia de los propios actores (Rendón \& Montaño, 2004; Rosa \& Contreras, 2007; Rosas, 2006), contrario al enfoque de las teorías organizacionales que se basan en planteamientos prescriptivos, positivistas, funcionalistas y pragmáticos (Morales, 2004; Zey, 1981).

Cabría preguntarse entonces, qué otras acciones en la gestión organizacional propician una concepción del hombres como un ser activo, capaz de transformar las circunstancias que lo rodean de manera consciente, digno de respeto y participación, bajo los principios de equidad, libertad y responsabilidad: con capacidad de decisión, autonomía, aprendizaje y desarrollo; siendo parte de la organización como un sujeto creativo que contribuye al alcance de la misión y visión organizacional, y a la vez busca estados de realización personal (Aktouf, 2004; Bendassolli, 2011; Maciel, Hopfer, \& Souza- Lima, 2004; MarínIdarrága, 2006).

Teniendo en cuenta estas apreciaciones e interrogantes sobre la gestión humana, nuestra propuesta pretende ir más allá de un orden funcional e instrumental, sin desconocer la importancia que esto tiene en sus resultados. Al respecto, Aktouf (2009, p. 29) plantea la necesidad de comprender que "las herramientas administrativas y las sofisticaciones tecnológicas no son nada si no hay un clima social y humano propicio para la adhesión, la colaboración y el rendimiento", sugiriendo, que no es que haya que omitir los instrumentos o las técnicas administrativas, sino que "debemos servirnos de ellas y no servirles".

Lo anterior propone pensar una filosofía de gestión que transcienda los criterios de la eficiencia y eficacia, y establezca, un marco de referencia conceptual que genere la reflexión sobre la razón de ser, el porqué y los para qué de los comportamientos en la organización. En este sentido, la filosofía de gestión “plantea dudas, formula preguntas y señala incoherencias provenientes de la propia diversidad que caracteriza a las organizaciones sociales complejas, en un entorno incierto y cambiante" (Etkin, 2007 , p. 21). Esto implica que son ideas que no pertenecen a un grupo de interés o influencia en especial, sino que involucra a la organización en su conjunto, donde subyace no un saber individual sino un saber compartido.

Así pues consideramos que la gestión humana tiene la responsabilidad de mediar las relaciones socio-laborales que se presentan en la organización. Entendiendo la mediación como aquel proceso que permite incluir los diferentes actores de interés en la búsqueda conjunta de alternativas para el manejo de conflictos, toma de decisiones y establecimiento de acuerdos y así facilitar la comprensión de las dinámicas y determinantes de las relaciones socio-laborales (Lopera, Ramírez, Zuluaga, \& Ortiz, 2010a) y contribuir en la construcción de una ética organizacional (Gama, Mckenna, \& Peticca-Harris, 2010; Martiningo \& Siqueira, 2008). 


\section{MÉTODO ANALÍTICO}

Entendiendo el análisis como un procedimiento para llegar a la comprensión mediante la descomposición de un fenómeno en sus elementos constitutivos (Lopera et al., 2010b), y el método científico como la "contrastación dialéctica entre la teoría y la práctica” (Ramírez, 1991, p. 35), concebiremos el método analítico como "un método científico de análisis del discurso basado en unos procedimientos generales que se aplican en el caso por caso a partir de la escucha de una situación concreta" (Ramírez, 2011, p. 573). Desde esta perspectiva, el método será entendido como una actitud que privilegia los procedimientos abiertos, con supuestos flexibles y modificables (indogmáticos), en armonía con el devenir de las situaciones.

Para referirnos al método analítico en el análisis del discurso es importante explicar cómo entenderemos el concepto discurso. Llamaremos discurso a "toda expresión de una estructura subjetiva" (Lopera et al., 2010a, p. 46), la cual se puede dar de manera verbal o no verbal, indicando que es un sujeto el que se expresa, sea individual, grupal (grupo o equipo) o colectivo (organización o comunidad). En el marco de esta propuesta, el sujeto individual será entendido como el colaborador que establece un vínculo con la organización, el sujeto plural como el grupo de trabajo que se conforma en la dinámica de la organización y el sujeto colectivo como la organización en general. Cabe señalar que la palabra “expresión” se abordará de una manera amplia, aludiendo no solo a lo dicho en palabras, sino también a otras formas de comunicar, como los gestos, la escritura, las formalizaciones teóricas, entre otras, generando significaciones y sentidos (Lopera et al., 2010a) Tales aspectos serán fundamentales al momento de comprender las realidades organizacionales.

Para llevar a cabo la aplicación del método analítico en el análisis del discurso, Ramírez (2012) sugiere implementar cuatro procesos, aclarando que no se trata de pasos secuenciales sino de formas distintas de acercarse a un discurso que, al ser conjugadas, brindan mayores posibilidades para el análisis. Estos procesos son: entender, captar el sentido y la lógica interna que compone un discurso determinado; criticar, comparar las diferentes partes del discurso que se están analizando para determinar su consistencia y coherencia; contrastar, que se realiza acudiendo a la experiencia, verificando en la práctica los efectos de un discurso determinado, es decir, su eficacia; e incorporar, que hace referencia a que en la medida que se analiza un discurso, se va asumiendo un nuevo modo de proceder en el que se hacen propios los valores y estilos que son acordes con nuestro ser (Lopera et al., 2010a).

Si bien es cierto que un método puede ser entendido como una serie de pasos para lograr un fin determinado (algoritmo), nosotros lo concebimos como una forma de proceder, una actitud. Según Ramírez (2011, p. 573), una actitud es "una disposición de ánimo, que se expresa mediante palabras o hechos: en las acciones, los gestos, la postura, el modo de ser y comportarse de un sujeto". Las actitudes tienen tres componentes que se relacionan entre sí: el cognitivo, el afectivo, el emocional o sentimental y el comportamiento (Robbins, 2009). En la convergencia de estos componentes emergen aspectos como la intuición, la inspiración, la invención y el ingenio (Lopera et al., 2010a), los cuales no pueden ser predeterminados desde un algoritmo o un procedimiento.

\section{Diseño metodológico}

Como objetivo general buscamos formalizar una propuesta teórica de la gestión humana de orientación analítica, basada en una concepción de hombre en la organización que privilegie la verbalización como camino a la responsabilización subjetiva. Para tal efecto, se tuvieron en cuenta principalmente presupuestos teóricos, articulados con un trabajo de campo que buscó identificar aspectos del quehacer profesional en esta área, realizando una contrastación dialéctica entre la teoría y la práctica.

Es importante precisar que esta investigación fue de tipo transversal, sin pretender un seguimiento en el tiempo. El alcance de la investigación fue exploratorio, desarrollando un tema poco estudiado y que desde el método analítico no ha sido abordado. El enfoque metodológico de la investigación es de carácter cualitativo privilegiando la descripción, comprensión e interpretación de los discursos hablados y escritos (Hernández, Fernández, \& Baptista, 2010); características propias de un diseño no experimental. Entendemos que el enfoque cualitativo:

Aborda las realidades subjetivas e intersubjetivas como objetos legítimos de conocimientos científicos. Busca comprender - desde la interioridad de los actores sociales- las lógicas de pensamiento que guían las acciones sociales. Estudia la dimensión interna y subjetiva de la realidad social como fuente de conocimiento (Galeano, 2004, p. 18).

Dicha comprensión de aquellas lógicas de pensamiento que guían las acciones sociales, se posibilita por medio de la aplicación del método hermenéutico, basado en la interpretación. Para Gadamer, interpretar:

[...] no es un acto complementario y posterior al de la comprensión, sino que comprender es 
siempre interpretar, y en consecuencia la interpretación es la forma explícita de la comprensión. [...] nuestras consideraciones nos fuerzan a admitir que en la comprensión siempre tiene lugar algo así como una aplicación del texto que se quiere comprender a la situación actual del intérprete (Gadamer, 1999, p. 378).

Adicional a la hermenéutica aplicamos el método analítico en el análisis del discurso, a partir de la descomposición de sus elementos y su posterior rearticulación, este proceso se realiza "tanto en un sentido diacrónico (que estudie la historia, la génesis y las sucesiones discursivas) como sincrónico (que tenga en cuenta el momento y la situación: el contexto actual, y busque las relaciones y conexiones con otros discursos)" (Ramírez, 2012, p. 99).

Se revisaron artículos tomados de bases de datos y publicaciones especializadas sobre el tema teniendo en cuenta autores representativos contemporáneos y clásicos. Se realizaron entrevistas semi-estructuradas a 9 líderes de gestión humana, entre los cuales se encontraban directivos, académicos y consultores; adicionalmente, se realizó una sesión de grupo de discusión compuesto por 16 profesionales que cursan un posgrado en gestión humana. Cada entrevista tuvo una duración aproximada de 1 hora y 45 minutos y fue realizada por dos de los investigadores, y el grupo de discusión tuvo una duración de 2 horas y 20 minutos y fue realizado por tres investigadores. La muestra fue seleccionada de acuerdo con los criterios de muestra por expertos (entrevistas) y por oportunidad (grupo de discusión) (Hernández et al., 2010). Los entrevistados se contactaron directamente y se les invitó a participar voluntariamente del estudio. Los participantes del grupo de discusión son estudiantes de un posgrado que cursan en la Universidad EAFIT a quienes se invitó a participar de manera voluntaria en el estudio, dado que se encontraban reunidos en un curso sobre las diferentes técnicas de investigación. Cada investigador asumió un rol: coordinador, co-coordinador y observador. Tanto las entrevistas como el grupo de discusión se llevaron a cabo en un solo encuentro y partieron de una serie de preguntas guía, lo cual permitió una orientación flexible de la conversación teniendo en cuenta la escucha de elementos emergentes. Los sujetos seleccionados cuentan con experiencia en organizaciones (entre 600 y 30.000 empleados), representativas de diferentes sectores de la economía del país: financiero, salud, educativo, manufactura, ONG, los cuales tienen formación en ciencias sociales y humanas e ingenierías (ver Tabla 1).

Tabla 1. Perfiles de los participantes de la investigación

\begin{tabular}{|c|c|c|c|c|c|c|c|c|c|c|}
\hline Entrevistado & 1 & 2 & 3 & 4 & 5 & 6 & 7 & 8 & 9 & $\begin{array}{l}\text { Grupo de } \\
\text { discusión }\end{array}$ \\
\hline Profesión & Psicólogo & Abogado & Abogado & Psicólogo & $\begin{array}{c}\text { Trabajador } \\
\text { social }\end{array}$ & Admin. & Psicólogo & $\begin{array}{l}\text { Trabajador } \\
\text { social }\end{array}$ & $\begin{array}{l}\text { Ingeniero } \\
\text { industrial, } \\
\text { Psicólogo }\end{array}$ & $\begin{array}{l}\text { Admin. (6) } \\
\text { Psicologos (5) } \\
\text { Abogados (2) } \\
\text { Ingeniero (1) } \\
\text { Musico (1) } \\
\text { Contador (1) }\end{array}$ \\
\hline $\begin{array}{c}\text { Años de } \\
\text { experiencia }\end{array}$ & $>10$ años & $>10$ años & $>10$ años & < 5 años & > 10 años & $>10$ años & $>10$ años & $>10$ años & $>10$ años & 5-10 años \\
\hline $\begin{array}{l}\text { Sector de } \\
\text { empresa } \\
\text { donde } \\
\text { trabaja }\end{array}$ & Servicios & Salud & Industrial & $\begin{array}{c}\text { Fundación } \\
\text { (ONG) }\end{array}$ & $\begin{array}{c}\text { Fundación } \\
\text { (ONG) }\end{array}$ & Financiero & Educativo & Educativo & $\begin{array}{l}\text { Servicios, } \\
\text { Educativo }\end{array}$ & $\begin{array}{l}\text { Servicios (4) } \\
\text { Comercial (4) } \\
\text { Financiero (3) } \\
\text { Educativo (1) } \\
\text { Salud (1) } \\
\text { Sin Datos (3) }\end{array}$ \\
\hline $\begin{array}{l}\text { Relación con } \\
\text { la academia }\end{array}$ & $\begin{array}{c}\text { Docente } \\
\text { posgrado }\end{array}$ & $\begin{array}{c}\text { Asesora } \\
\text { posgrado }\end{array}$ & $\begin{array}{c}\text { Docente } \\
\text { posgrado }\end{array}$ & N.A. & N.A. & N.A. & $\begin{array}{c}\text { Docente } \\
\text { posgrado, } \\
\text { Investigador }\end{array}$ & $\begin{array}{c}\text { Administrativo, } \\
\text { docente } \\
\text { posgrado }\end{array}$ & $\begin{array}{c}\text { Docente, } \\
\text { Investigador, } \\
\text { Consultor }\end{array}$ & $\begin{array}{c}\text { Estudiantes } \\
\text { posgrado }\end{array}$ \\
\hline Fecha & 29-ago-12 & 04-sep-12 & 12 -sep-12 & 17 -sep-12 & 17 -sep-12 & 09-nov-12 & 05 -dic-12 & 13-mar-13 & 01-oct-12 & 04-may-13 \\
\hline Duración & 01:10 & $02: 30$ & 01:15 & $01: 40$ & $01: 40$ & 01:30 & $01: 35$ & $01: 50$ & $01: 50$ & $02: 20$ \\
\hline
\end{tabular}


En la vía del método analítico y la hermenéutica, tomamos los criterios de codificación, análisis e interpretación de Coffey y Atkinson (2004, p. 58) para quienes “el proceso de codificación tiene que ver con hacerse preguntas acerca de los datos. Estas preguntas nos ayudan a desarrollar líneas de especulación y a formular hipótesis". Para Coffey y Atkinson (2004) luego de la codificación se pasa a la interpretación recuperando el contexto de los datos, que muchas veces se pierde en el proceso de su estructuración en categorías. Para el análisis de la información, basados en el marco teórico de esta investigación se establecieron las categorías iniciales que orientaron el diseño de los instrumentos: gestión humana, concepción de hombre, orientación analítica y espacios conversacionales, que al ser contrastadas con la información obtenida en el trabajo de campo generó categorías emergentes como: simbolización, socialización y responsabilización (ver Figura 1).

Cada entrevista y el grupo de discusión se grabaron en audio, se transcribieron, se codificaron y se categorizaron para facilitar el proceso de análisis. Una vez que se codificó el material, se procedió realizar la triangulación de datos (Hernández et al., 2010) mediante la contrastación entre la información obtenida en las entrevistas, los referentes teóricos y el proceso interpretativo del grupo investigador, que se reunió durante 87 sesiones de una hora y media semanales. De cada una de estas reuniones, se elaboró una relatoría en la cual se plasmaron las conclusiones de los análisis, y que fueron luego retomadas para la elaboración del informe final del estudio.

\section{Figura 1. Categorías de análisis de la investigación}

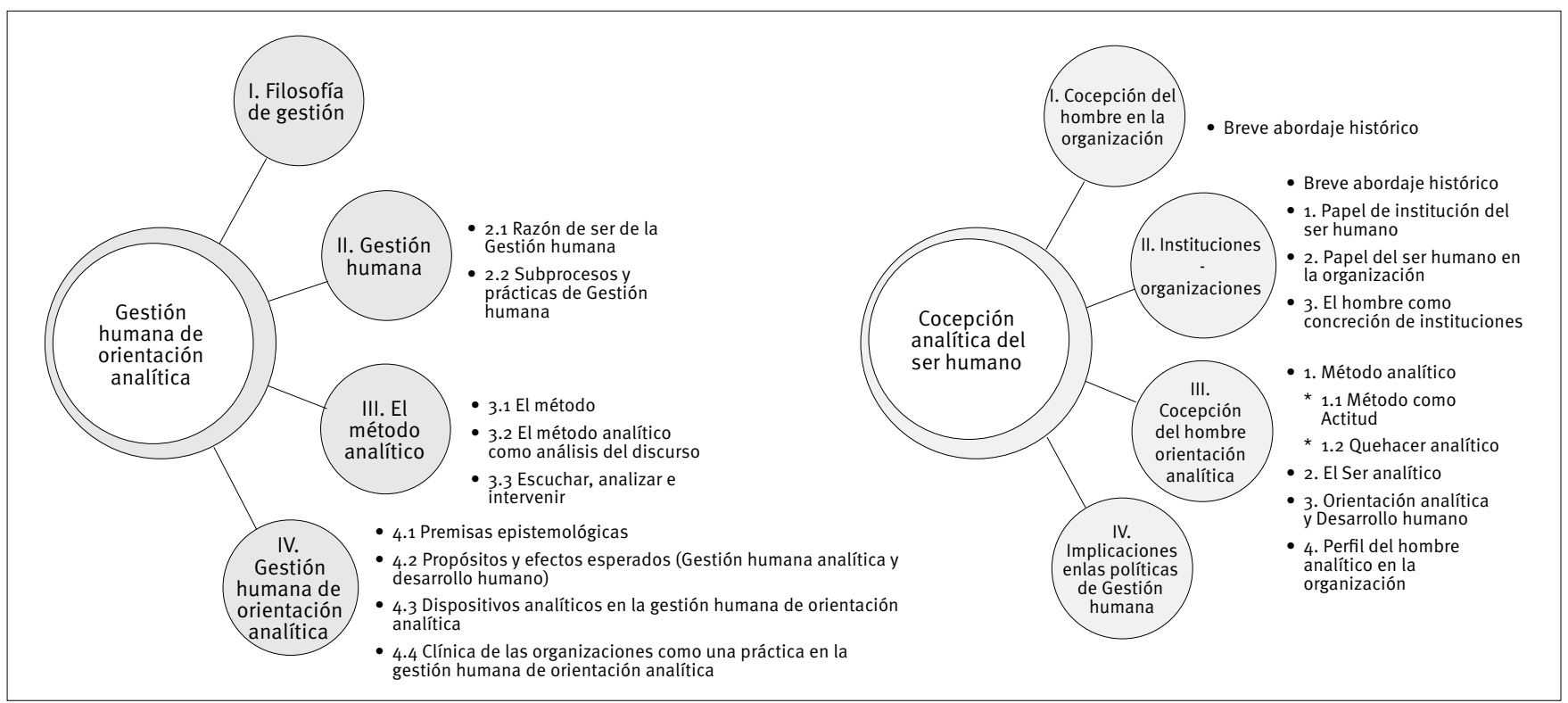

\section{Resultados: La orientación analítica en la gestión humana}

Preguntarse por el desarrollo del ser humano en el ámbito laboral, invita a trascender el pensamiento meramente instrumental y llegar a una concepción compleja de la organización, donde la apertura al saber, el análisis y la reflexión, son aspectos necesarios en la comprensión de los fenómenos sociales y humanos. Esta concepción incide en el comportamiento y desempeño laboral de los sujetos que conforman la organización. Dicho planteamiento está enmarcado en una filosofía de gestión que se pregunta por la relación entre la organización y el desarrollo social, integrando los procesos económicos, sociales, culturales y simbólicos, y abogando por una actitud fundada, responsable y comprometida con la calidad de vida de las organizaciones (Etkin, 2005, 2007). Una actitud soportada en una orientación analítica, que promueva el desarrollo humano y la responsabilización de los actores que interactúan en y con la organización en vía de una ética organizacional.

El pensar el desarrollo de una propuesta de gestión humana de orientación analítica, ha sido el resultado de constantes interrogantes sobre las formas, medios y prácticas que se llevan a cabo en el abordaje del ser humano en la organización. Hemos procurado comprender aquellos aspectos que posibilitan la interacción humana, privilegiando la escucha, el análisis y la intervención del discurso individual y grupal, por medio de espacios conversacionales que buscan generar procesos de responsabilización en la organización.

En este sentido, implementar una gestión humana bajo esta orientación supone contar con varias condiciones que permitan 
proceder de manera conveniente en las organizaciones por parte de los profesionales. En un primer momento, consideramos que es fundamental declarar la concepción de ser humano que se tendrá en la organización, ya que esta dará lugar a categorizaciones y significaciones conceptuales en torno a la gestión humana y, así, a los fundamentos de sus prácticas. Respecto a esta idea, uno de los entrevistados plantea:

[...] un trabajo importante que tendría gestión humana que hacer es ese, es lo primero que una organización necesita, y que gestión humana le tiene que ayudar a una organización, es a definir a qué tipo de hombre le va a apostar, y cuando ya en todas las mentes está a qué tipo de hombre se le está apostando, una intervención es que ya están buscando que yo sea ese tipo de hombre que la organización le está apuntando. [Los líderes de gestión humana y el gerente] son los que tienen que creer en esto para poder hacerlo realidad (Entrevista 1).

De acuerdo con lo anterior, Aktouf (2009) plantea cómo en la actualidad se ha dado una convergencia en las corrientes teóricas de la administración que apuntan a una organización más humanizada, donde se considere la centralidad de la persona, sus actitudes y comportamientos, sin antes haber manifestado la necesidad de plantear una teoría del ser humano que le dé sustento y sentido a las acciones que se desplegarán en el abordaje de los procesos humanos en la organización.

Desde nuestra propuesta consideramos al hombre como un animal verbal, el cual hace uso de la palabra como principio articulante de su realidad, esto es, logos (Lopera et al., 2010a, 2010b; Ramírez, 2012). El lenguaje será entendido como aquello constitutivo del ser humano como "una estructura que acoge y ordena la realidad humana, dándole su forma específica” (Lopera et al., 2010a, p. 128).

Ahora bien, entendemos el método analítico como un modo de proceder para acceder a las lógicas de los discursos individuales o grupales. De esta manera la orientación analítica en la gestión humana se fundamenta, no en la utilización de una teoría determinada, sino en la aplicación de un método, una actitud soportada en el quehacer analítico, compuesto por tres acciones: escuchar, analizar e intervenir, conjugándose de manera que no existe un orden cronológico para realizarlas, sino que convergen en la acción, por lo que separarlas es solo un recurso que facilita su comprensión.

En el trabajo de campo realizado en el marco de esta investigación, se evidenció cómo algunos líderes de gestión humana proceden desde una perspectiva analítica al favorecer la escucha en sus prácticas cotidianas en la organización, lo cual se percibe en las siguientes palabras de un entrevistado:

[...] hemos creado un lema dentro del grupo y lo hemos dicho en la publicidad [de nuestra empresa]: "no es lo mismo hablar que conversar, no es lo mismo oír que escuchar". Estamos estableciendo esas diferencias porque no es lo mismo que yo esté en una reunión con un equipo de trabajo, pero esté pendiente de mi BlackBerry o de mi Iphone, chateando, haciendo el que escucho, pero no escucho, sino que estoy oyendo un ruido que el otro produce. En la cultura estamos intentando que la gente cuando esté escuchando al otro, lo esté escuchando auténticamente, desde la emoción, desde el lenguaje y desde el cuerpo, que esté presente en estos tres elementos (Entrevistado 5).

De esta manera, entendemos que escuchar es fundamentalmente una apertura al discurso del otro, caracterizada por una actitud que permite captar diversas manifestaciones discursivas, así como el contenido latente y manifiesto de las expresiones. La escucha involucra todos los sentidos. Como acto que va más allá del oír, permite un sentir comprensivo, es decir, una captación holística de la situación. La confluencia de todos los sentidos, anudada a las propias representaciones de lo analítico, permite obtener un saber más completo, sin limitarlo a las expresiones fonéticas (Lopera et al., 2010a).

Destacando la importancia que tiene la palabra en el proceder de los dirigentes y de los profesionales que conducen las organizaciones, desde una orientación analítica la palabra y la escucha no serán consideradas como un mecanismo simulado de participación, sino como un medio de transformación subjetiva que le permite a los sujetos y a los grupos saber algo más de sí mismos, de la organización y del lugar que allí ocupan (Henao, 2008), y en esta medida, brindar condiciones que posibiliten su proceso de responsabilización, del cual hablaremos más adelante.

Analizar implica descomponer un discurso en sus elementos básicos, establecer relaciones entre ellos y generar nuevas asociaciones que la captación directa, a través de los sentidos, no permite. El proceso de análisis no excluye la síntesis, ambos permiten acceder a una articulación de conocimiento comprensiva, sin limitarse al saber intelectual y racional. Uno de los entrevistados plantea, refiriéndose a los errores que se presentan en un proceso de selección, que:

[...] nuestro dolor de cabeza era cuando se cometía un error en la evaluación y después veía- 
mos algo, [...] y nos sentábamos a analizar y decíamos: es que la mirada de ella [la responsable de hacer la selección] es una mirada superficial, ella mira el resultado de la prueba, ella mira lo que la persona le dice, [pero] ella no hace el análisis del discurso, y lo correlaciona con la información (Entrevista 1).

Así como escuchar los discursos en los sujetos individuales y grupales es importante en su proceder, el analítico ha de analizarlos teniendo en cuenta el momento y la situación en la que se presentan. Capta los sentidos implícitos de los discursos manifiestos (Andrade, 2013), permitiendo mediar en la situación, dándole paso al tercer proceso que es el de la intervención. Las palabras de un entrevistado soportan lo dicho:

El encargo es, como su nombre lo indica, el pedido original que hace un grupo gestor, una persona o un grupo gestor que viene con una hipótesis que dice "pasa esto, y queremos tal cosa"; [...] porque no necesariamente vienen y te dicen "pasa esto", sino que dicen "me duele, me preocupa", y ese es el encargo tipológicamente, además significa que te pone el encargo de dar respuesta a esa necesidad, [...] significa incorporar todas aquellas partes involucradas en esa definición de la necesidad o en esa definición de la situación y, a vuelta de correo, reformular ese encargo y eso significa transformarlo de algún modo (Entrevista 9).

Ahora bien, el desempeño de los profesionales en las realidades organizacionales está mediado por las intervenciones que realizan en su quehacer laboral, basado por aquellas capacidades que contribuyen al logro de los objetivos de manera efectiva. Lo anterior se evidencia cuando un entrevistado habla sobre la manera de intervenir de los jefes en su organización:

[...] la participación es muy importante, es muy claro que todos hacemos cosas muy buenas cuando todos aportamos. Aquí el jefe no le dice: "venga, qué tiene que hacer, no, [dice]: "venga sentémonos y construyamos juntos". Eso requiere un manejo, que haya un manejo muy especial de poder, no de "yo mando aquí", sino de "construyamos juntos (entrevista 4).

Desde nuestra perspectiva, la intervención no está representada solamente por los aspectos generales, sino también por aquellos que le dan cabida a los elementos específicos de las situaciones, al caso por caso. Entendemos intervenir como las acciones que se generan a partir de lo escuchado, donde el sujeto decide obrar analizando los elementos, ya sean descubiertos o re-elaborados. La formación continua en el análisis del discurso puede llevar a intervenciones cada vez más adecuadas a partir de la actitud analítica que se ha incorporado. En palabras de Lopera et al. (2010a, p. 164): “La adecuación se define en cada situación de acuerdo con los propósitos que se tengan”. La formación hará que el analítico escuche más, analice con profundidad y haga intervenciones más adecuadas.

Al analizar los discursos que se presentan en la organización, se captan y analizan elementos implícitos que hay alli presentes, los cuales pueden estar parcializados por efectos de imaginaciones, ideas preconcebidas o prejuicios. Cuando hablamos de prejuicios (Ramírez, 2012), hacemos referencia a todos aquellos valores que hemos ido incorporando en el transcurso de la vida sin procesos previos de reflexión, sin haber analizado dichos juicios. Es muy común que los sujetos lleguen a las organizaciones con una serie de concepciones del mundo sobre las cuales soportan su proceder, considerando en muchas ocasiones que son la única manera de entender y comprender las realidades que los circunscriben. Esta situación llega a ser problemática y genera malos entendidos cuando se interpretan las expresiones de los demás, sin entender sus argumentos o lo que está queriendo decir. En este tipo de casos, analizar por qué se hizo dicha interpretación o cómo un sujeto adoptó cierta opinión, será importante para captar aquellos elementos implícitos. Es tarea entonces del analítico propiciar espacios de diálogo, de discusión, en los que los sujetos puedan verbalizar, intentando explicitar aquellos contenidos implícitos que puedan ser analizados (Ramírez, 2012).

\section{Concepción del hombre}

En nuestra propuesta de una gestión humana de orientación analítica entendemos la importancia de plantear una concepción de hombre que le dé sentido y sustento a las prácticas de gestión humana en la organización (Bermúdez, 2011). De esta manera partiremos de aquellos presupuestos particularmente humanos como lo son el lenguaje y específicamente el uso de la palabra, concibiendo al hombre como un animal verbal, un ser en relación, que habita un universo simbólico en su interacción con el otro, comunicando un discurso con contenidos manifiestos y latentes. Esto implica entenderlo como un hijo del lenguaje que a través de la verbalización simboliza, socializa y se responsabiliza (Zapata, 1995).

Es precisamente este interés por la palabra el que fundamenta el proceder de la gestión humana al propiciar 
prácticas donde el discurso del sujeto se resignifica, abriendo el camino a la construcción propia y genuina de su identidad. Un profesional analítico escuchará a los demás dándoles un lugar desde su singularidad, sin desconocer las lógicas organizacionales en las que está circunscrito; esto le permitirá a cada persona entender las dialécticas que subyacen en las relaciones socio-laborales. A propósito de este planteamiento, Bédard (2003, p. 74) habla de la importancia de:

[...] elaborar un enfoque que reconozca, de un lado, el lugar central del ser humano en general y, del otro, tenga en cuenta las particularidades individuales, lo que implica no solamente comprender las características propias de la especie humana, sino también respetar y valorizar las potencialidades específicas de las personas, que son la fuente de la fecundidad del grupo.

Reconocer y darle un lugar importante a las particularidades individuales en la organización, es un camino para favorecer el proceso de singularización. Esto proceso considera aquellos aspectos singulares que caracterizan la construcción genuina de su identidad subjetiva, favoreciendo el desarrollo de las potencialidades, en tanto individuo, grupo u organización. Entenderemos que la singularización parte de la voluntad del sujeto, anudado a las posibilidades que este tenga, las cuales pueden ser propiciadas por la organización. El lugar que se le da a las particularidades individuales, es uno los principios que orienten las acciones de una gestión humana analítica, expresado por uno de los entrevistados:

[...] yo pienso que el verdadero papel de un área de gestión humana en una organización debe estar orientada a propiciar [...] la humanización realmente en la empresa y, ¿qué es la humanización?, fundamentalmente darle el lugar al otro, al ser humano, todo lo que implica su dignidad, su libertad, su identidad, su crecimiento, su aceptación, [...]; hay muchas cosas más que dedicarse a hacer un montón de tareas instrumentales, que en un momento dado se pueden subcontratar (Entrevista 7).

Desde nuestra propuesta una de las vías para potencializar este desarrollo es la verbalización, considerando la palabra hablada como el elemento esencial para la transformación subjetiva, ya que la verbalización produce efectos de articulación en la que los contenidos imaginarios adquieren una organización diferente al ser expresados, teniendo como efecto la simbolización, la socialización y la responsabilización (Zapata, 1995). Cuando las prácticas de gestión humana propician espacios de participación, discusión, conversación, se le dará un lugar esencial a la verbalización, considerando al sujeto como un actor activo, con capacidad de escucha, reflexión, capaz de darle un lugar al otro incluyéndolo en los procesos de toma de decisiones, responsabilizándose por las acciones tomadas (Freitas, Aquino, \& Pesqueux, 2012).

La simbolización favorece la organización de las representaciones mentales, a través de imágenes que no han sido organizadas. Al pasar del registro imaginario al simbólico, es decir, de las imágenes a las palabras, se realizan asociaciones y ligan elementos que no han sido articulados en los demás componentes del discurso del sujeto. La verbalización, o expresión en palabras comprensibles, actualiza dicho proceso (Zapata, 1995), buscando la reconstrucción del discurso subjetivo, y no la repetición de palabras sin sentido o "hablar por hablar"; representando aquello que se halla en el plano imaginario, lo que implica que el sujeto en las organizaciones pueda materializar lo implícito en un saber comprensible para el otro, pasando de las imágenes mentales a la palabra articulada con un significado.

Es importante resaltar lo nocivo que puede llegar a ser la actitud de aquellos profesionales que no privilegian la simbolización en el trabajo con los otros, dando pie a temores, fantasías, prejuicios que puedan impedir que el sujeto hable, afectando las dinámicas laborales:

[...] Entonces el miedo en un equipo de trabajo lo que hace es silenciar a la gente y, en últimas, hace mucho daño para los resultados, porque cuando el ser humano no es capaz de hablar lo que tiene que hablar, se guarda las cosas importantes, y eso evita que el resultado sea más efectivo que si pudieran conversar de lo que le está afectando de las cosas, [lo cual] puede mejorar el desempeño del equipo (entrevista 6).

Por su parte, la socialización posibilita la interacción social y el establecimiento del pacto social, reconociendo la presencia del otro en tanto agente socializador. Dicha afirmación la podemos percibir en la concepción de ser humano que se tiene en la organización de uno de los entrevistados:

[...] Entendemos la naturaleza social del ser humano, creemos que no existimos como partes aisladas, que la esencia de la existencia humana es la relación con otros, concebimos al hombre 
como un ser en proceso permanente de transformación a través de la vida (entrevista 3).

Según Zapata (1995, p. 9), la socialización se entiende como: “la expresión en palabras comprensibles por otros de los símbolos construidos a nivel individual, lo cual enfatiza el aspecto de la interacción y del sujeto en tanto perteneciente a un pacto social". En las organizaciones se establecen pactos de manera formal e informal, generando diferentes consecuencias en las dinámicas socio-laborales. Un ejemplo de pacto formal son los procesos de contratación, los cuales formalizan el vínculo laboral, explicitando el compromiso que cada una de las partes deberá asumir con el otro. Cuando este se verbaliza, permite establecer acuerdos consensuados entre los colaboradores posibilitando espacios de participación, generando compromiso y estableciendo procesos de responsabilización por medio de la palabra. Lo anterior lo podemos percibir en el siguiente apartado de una entrevista:

[...] afortunadamente hemos estado con un equipo de trabajo en el que nos entendemos muy bien, pero llega un punto en el que [alguien] no saludó, miró feo, pero miró feo porque se le acabó de quitar un candidato del proceso, y muchas veces lo que pactamos nosotros como equipo de trabajo era: todo conversado es mejor, no es que miró feo y lleva una semana sin hablar, no, [es]: "vení, conversemos" y eso es por ejemplo lo que tratamos de hacer hoy en día, si hay algún conflicto dentro del equipo de trabajo, que afortunadamente no es como del común, tratamos de hablarlo nosotras, [...] hoy como por política lo que nosotros implementamos fue eso (Grupo de discusión).

Asimismo, la Socialización facilita la participación activa de los colaboradores en los escenarios organizacionales, especialmente en los espacios grupales (Bertland, 2011). Esto les otorga un lugar en las conversaciones y discusiones, brindando posibilidades para fortalecer su expresión en público y responsabilizando a cada persona de su papel en el grupo y en la organización. La responsabilidad se entiende en doble vía, de la organización hacia el colaborador y de este hacia ella (Henao, 2008).

Finalmente, la responsabilización se da como consecuencia de la asunción del sujeto de su propio deseo en el acto de socialización que implica verbalizar, es decir, cuando un sujeto pone en palabras su discurso asume un compromiso con él mismo y con el otro que lo escucha. En el escenario organizacional es propicio crear espacios de conversación, ya que a través de la palabra es como el sujeto logra dirigirse al otro desde su propia subjetividad (Zapata, 1995).

De esta manera será entonces objeto de la gestión humana de orientación analítica brindar aquellas condiciones necesarias para contribuir en la responsabilización de los sujetos que forman parte de la organización, es decir, que estén en la capacidad de asumir los propios actos, comportamientos, deseos y desempeños, reconociendo que hay una parte al menos de lo que les ocurre de la cual son responsables directos, y en esa medida, dejar de culpar o responsabilizar a los demás, a las circunstancias, a las situaciones o a la vida misma (Ramírez, 2012). Vemos cómo en la cotidianidad de las organizaciones emergen actitudes de desresponsabilización tal como lo plantea un entrevistado:

[...] aquí hemos declarado un lema "no admitimos los echa culpa", [...] Un echa culpa es una persona que no asume la responsabilidad ni de sus acciones, ni de relaciones, ni de sus decisiones, sino que le está echando la culpa a otras cosas, a la competencia, a sus compañeros, a su jefe, a su familia, a sus amigos, todo el mundo tiene la culpa de lo que les pasa, si eliminamos de raíz los echa culpa cada uno asume la responsabilidad de lo suyo y entra al equipo asumiendo esa responsabilidad (Entrevista 5).

La responsabilización implica comprender que el centro y el núcleo de un entorno como la organización, es el sujeto singular, por ello, este proceso inicia con la singularización, momento en el cual el sujeto se hace responsable de su propio discurso y de su destino (Ramírez, 2012). Acorde con este planteamiento Chanlat (2002, p. 81) aclara que:

Una persona responsable es una persona que trata de anticipar, en la medida de sus posibilidades, las consecuencias que tendrán sus actos para el otro. Dicha postura es muy exigente, sobre todo en un contexto donde no todo es comprendido o controlado, pero es esencial para la supervivencia de la vida colectiva.

En la dinámica organizacional la responsabilización requiere de la generación de espacios de conversación y diálogo con el propósito de contribuir a la solución de conflictos y tensiones, esperando de esta manera propiciar condiciones que favorezcan al mejoramiento del desempeño tanto del individuo como del grupo. Al respecto, un entrevistado comenta: 
[...] evitar que esos equipos terminen peleando, odiándose: 'no..., es que los de operaciones son unos... porque no cumplen'. Aquí no le vamos a echar la culpa a nadie de lo que nos está pasando, sentémonos a conversar de qué es lo que estamos haciendo los unos y los otros y, desde la conversación y el diálogo lleguemos a acuerdos (Entrevista 5).

Es importante tener presente que en el proceso de la responsabilización se incluye la simbolización y la socialización, dado que a través de estos se establecen acuerdos mediados por la palabra, en donde un sujeto responsable ha de asumir sus palabras obrando consecuentemente con los compromisos, pactos o acuerdos establecidos. Es por esto que la verbalización conduce a la transformación del sujeto y a la asunción responsable de su existencia:

Cuando uno empieza a ver seres más responsables, son seres que transcienden más hacia su equipo, “son más, para servir mejor al equipo", entonces uno no está viendo gente que está tratando de brillar atropellando al otro [...] o seres que no hablan por temor, sino que todos se sienten en esa responsabilidad por los resultados (Entrevista 5).

\section{CONCLUSIONES}

Teniendo en cuenta el objetivo de este artículo que, como se planteó anteriormente, es presentar la formulación de una propuesta de gestión humana que le apuesta al desarrollo humano en la organización, a continuación precisaremos las conclusiones arrojadas que están agrupadas en dos aspectos centrales (ver Figura 2).

En primer lugar, la necesidad de contar con una filosofía de gestión que legitime el tipo de orientación analítica en la organización que proponemos aquí, y así mismo, fundamentar la transmisión de las actitudes necesarias para formalizar espacios de conversación, que aboguen por la participación del sujeto a través de la palabra, como una vía para potencializar su desarrollo, fundamento de la propuesta de una gestión humana de orientación analítica.

El interés de una gestión humana de orientación analítica de promover estos dispositivos de desarrollo en la organización, está fundamentado en una concepción del hombre, así como en la actitud analítica de aquellos profesionales que tienen bajo su responsabilidad la mediación de las relaciones socio-laborales. Es importante precisar que esta gestión humana no se limita a las acciones globales, medibles por indicadores cuantitativos, sino que consiste en una forma de proceder, una praxis donde se toma en cuenta al otro y se le da un lugar, reconociéndolo como sujeto activo y responsable, favoreciendo el desarrollo humano desde acciones simples, cotidianas, que se construyen alrededor de la palabra.

Por lo tanto, creemos que el escuchar al sujeto en la organización permite darle un lugar en calidad de actor, reconocerlo, donde las relaciones laborales podrán establecerse en términos de igualdad (Islam, 2012; Muñoz, 2002). Al respecto, dice Pierre Bruneau: “Entre mandar y obedecer, la posibilidad de hablar funda el reconocimiento del hombre como sujeto, constituyendo a quienes mandan y quienes obedecen en una igualdad de valor" (Bruneau, 1991, p. 97).

En segundo lugar, esta propuesta permite plantear una vía para la ética organizacional, en la que la organización dispone las condiciones y los espacios para que ella misma, los individuos y los grupos asuman sus actos de manera responsable, estableciendo una dialéctica entre los diferentes actores, que unidos bajo el principio de corresponsabilidad tienen en cuenta los intereses generales y particulares, siendo consecuentes con sus propios actos al integrar el creer, el sentir, el pensar, el expresar y el decir (Ramírez, 2011).

En consecuencia consideramos que una organización que abogue por la responsabilización de sus colaboradores, estará actuando de manera sostenible, basada en una responsabilidad social empresarial como lo indica uno de los entrevistados al decir "[...] la responsabilidad social en las organizaciones tiene que empezar por su gente" (Entrevista 4).

El alcance y las limitaciones del presente estudio no permiten la generalización de sus resultados, dado el tamaño de la muestra. Sin embargo, tenemos presente que en la investigación cualitativa lo importante no es la representatividad estadística de la muestra ni la generalización de los resultados, sino la significación y profundidad de los datos recolectados para lograr la saturación de categorías (Hernández et al., 2010). Adicionalmente, este artículo parte de un trabajo predominantemente teórico que quisimos contrastar con lo que se vive diariamente en las organizaciones desde la perspectiva de los directivos y trabajadores de las áreas de gestión humana. Para una próxima investigación en esta línea, sería interesante contrastar la relación entre gestión humana de orientación analítica con prácticas de responsabilidad social empresarial, procesos de mediación en las organizaciones, toma de decisiones, formación empresarial y generación de conocimiento, trabajo con grupos y creación de programas de desarrollo humano en la organización. 
Figura 2. Propuesta de Gestión humana de orientación analítica

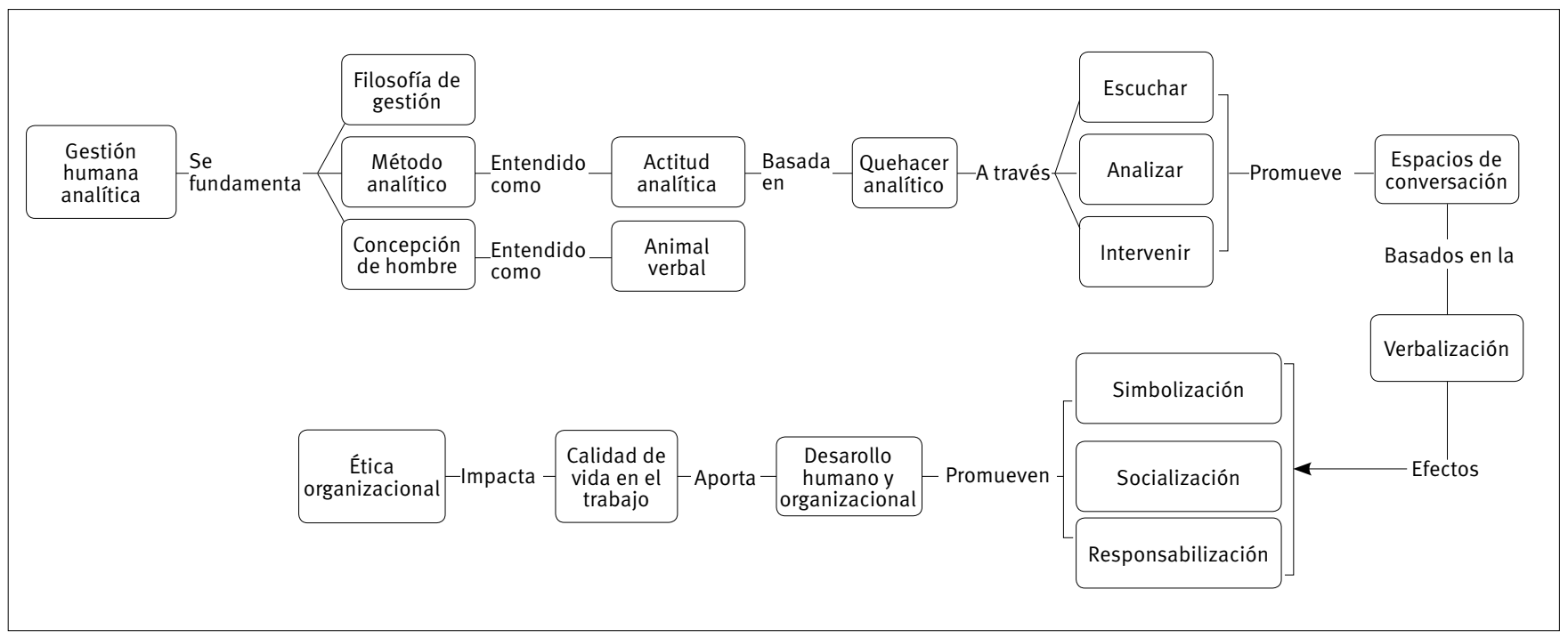

\section{REFERENCIAS}

Aktouf, 0. (2000). Administración y pedagogía. Medellín: Fondo Editorial Universidad EAFIT.

Aktouf, 0. (2004). La estrategia del avestruz: Post-globalización, management y racionalidad económica. Cali: Universidad del Valle - Artes Gráficas del Valle.

Aktouf, O. (2009). La administración: Entre tradición y renovación. Cali: Artes Gráficas del Valle.

Alfalla-Luque, R., Marín-García, J., \& Medina-López, C. (2012). Is worker commitment necessary for achieving competitive advantage and customer satisfaction when companies use HRM and TQM practices? Universia Business Review. Recuperado de https://ubr.universia. net/

Andrade, V. (2013). Creando subjetividades laborales: Implicaciones del discurso psicológico en el mundo del trabajo y las organizaciones. Psicologia \& Sociedade, 25(1), 185-192. doi:10.1590/ s0102-71822013000100020

Aragón, A., Tenorio, J., Pérez, M., Sabater, R., Sánchez, G., \& Sanz, R. (2004). Fundamentos de dirección y gestión de recursos humanos. Madrid: Thomson.

Aubert, N., \& Gaulejac, V. De. (1993). El coste de la excelencia. Barcelona: Paidós.

Bédard, R. (2003). Los fundamentos del pensamiento y las prácticas administrativas: El rombo y las cuatro dimensiones filosóficas. Revista Ad-administer, (3), 68-87.

Bédard, R. (2004). Los fundamentos del pensamiento y de las prácticas administrativas 2: La trilogía administrativa. Ad-administer, (4), 80108.

Bendassolli, P. (2011). Mal-estar no trabalho: Do sofrimento ao poder de agir. Mal-estar e Subjetividade - Fortaleza, (1), 63-98.

Bendassolli, P. E., \& Soboll, L. (Orgs.). (2011). Clínicas do trabalho: Novas perspectivas para compreensão do trabalho na actualidade. São Paulo: Atlas.
Bermúdez, H. (2010). ¿Es posible pensar una gestión humana no funcionalista? Descripción de un modelo estratégico de gestión de personal. Revista Universidad \& Empresa, 12 (18), 174-202.

Bermúdez, H. (2011). La inducción general en la empresa: Entre un proceso administrativo y un fenómeno sociológico. Revista Universidad \& Empresa, (21), 117-142.

Bertland, A. (2011). The limits of workplace community: Jean-Luc Nancy and the possibility of teambuilding. Journal of Business Ethics, 99(2011), 1-8. doi:10.1007/s10551-011-1156-7

Bruneau, J. (1991). Psicoanálisis y empresa: Cómo utilizar el psicoanálisis para comprender la empresa. Buenos Aires: Granica.

Calderón, G., Álvarez, C., \& Naranjo, J. (2006). Gestión humana en las organizaciones un fenómeno complejo: Evolución, retos, tendencias y perspectivas de investigación. Cuadernos de Administración, 19(32), 225-254.

Calderón, G., Naranjo, J., \& Álvarez. C. (2007). La gestión humana en Colombia: Características y tendencias de la práctica y de la investigación. Estudios Gerenciales, 23(103), 39-64.

Chanlat, J. (2002). Ciencias sociales y administración. Medellín: Fondo Editorial Universidad EAFIT.

Chanlat, A., \& Bedard, R. (1997). La administración una cuestión de palabra. Tecnología Administrativa, 25, 179-219.

Coffey, A., \& Atkinson, P. (2004). Encontrar el sentido a los datos cualitativos: Estrategias complementarias de investigación. Medellín: Editorial Universidad de Antioquia.

Crane, A. (2013). Modern slavery as a managment practice: Exploring the conditions and capabilities for human explotation. Academy of Management Review, 38(1), 49-69. doi:10.5465/amr.2011.0145

Cuevas, R. (2009). Ética y responsabilidad social de la empresa: Su concepción de hombre. Polis, Revista de la Universidad Bolivariana, 8(23), 323-349.

Dessler, G. (2001). Administración de personal. México: Pearson.

Etkin, J. (2005). Gestión de la complejidad en las organizaciones. Buenos Aires: Granica. 
Etkin, J. (2007). Capital social y valores en la organización sustentable. Buenos Aires: Granica.

Freitas, I., Aquino, M., \& Pesqueux, Y. (2012). Responsabilidade social corporativa e desenvolvimento sustentável: Olhares habermasianos. RAE-Revista de Administração de Empresas, 52(2), 148-152. doi:10.1590_s0034-75902012000200002

Friedmann, G. (1956). Problemas humanos del maquinismo industrial. Bueno Aires: Sudamericana.

Gadamer, H. (1999). Verdad y método I. Salamanca: Sígueme.

Galeano, E. (2004). Diseño de proyectos de investigación cualitativa. Medellín: Fondo Editorial Universidad EAFIT.

Gama, N. De, McKenna, S., \& Peticca-Harris, A. (2012). Ethics and HRM: Theoretical and conceptual analysis. An alternative approach to ethical HRM through the discourse and lived experiences of HR professionals. Journal of Business Ethics, 111(1), 97-108. doi:10.1007/ S10551-012-1479-Z

García, M. (2009). Los macro-procesos: Un nuevo enfoque en el estudio de la gestión humana. Pensamiento y Gestión, (27), 162-200.

Henao, C. (2008). Coordinación grupal y relaciones de poder: Una aplicación del método analítico en las organizaciones. Medellín: Fondo Editorial Universidad EAFIT.

Hernández, R., Fernández, C., \& Baptista, P. (2010). Metodología de la investigación (5a ed.). México, D. F.: Mc-Graw Hill.

Islam, G. (2012). Recognition, reification, and practices of forgetting: Ethical implications of human resource management. Journal of Business Ethics, 111(1), 37-48. doi:10.1007/s10551-012-1433-0

Kliksberg, B. (1995). El pensamiento organizativo: De los dogmas al nuevo paradigma gerencial. Buenos Aires: Tesis.

Lopera, J., Ramírez, C., Zuluaga, M., \& Ortiz, J. (2010a). El método analítico. Medellín: CISH - U de A.

Lopera, J., Ramírez, C., Zuluag, M., \& Ortiz, J. (2010b). El método analítico como método natural. Nómadas. Revista Crítica de Ciencias Sociales y Jurídicas, 25(1), 1-27.

Maciel, S., Hopefer, K., \& Souza-Lima, J. (2004). Complementaridade entre racionalidades na construção da identidade profissional. RAEeletrônica, 3(2). Recuperado de http://rae.fgv.br/rae-eletronica/

Malvezzi, S. (2012a). El desempeño en la era de las empresas-red: Desafíos para la investigación de la subjetividad. En S. Malvezzi, J. Orejuela, R. Chiuzi, J. Vesga, \& W. Riascos. Gramáticas actuales de la relación hombre - trabajo: Propuestas de lectura. Cali: Editorial Bonaventuriana.

Malvezzi, S. (2012b). O trabalho traz felicidade? Revista Marketing industrial, (56). Recuperado de http://www.imi.org.br/revista_ detalhe. aspx?id=170

Manrique, H., \& Ramirez, V. (2014). Método clínico y trabajo analítico con grupos. [En publicación].

Manrique, H., Lopera, I., \& Perez, J. (2014). Clínica analítica de las organizaciones. [En publicación].

Manrique, H., Lopera, I., Perez, J., Ramirez, V., \& Henao, C. (2014). Clínica de las organizaciones: Una aplicación del método analítico. Artículo en preparación.

March, J., \& Simon, H. (1961). Teoría de la organización. Barcelona: Ariel.
Marín-Idárraga, D. (2006). El sujeto humano en la administración: Una mirada crítica. Cuadernos de Administración, 19(23), 135-156.

Martiningo, A., \& Siqueira, M. V. S. (2008). Assédio moral e gestão de pessoas: Uma análise do assédio moral nas organizações e o papel da área de gestão de pessoas. RAM-Revista de Administração Mackenzie, 9(5), 11-34. doi:10.1590/s1678-69712008000500002

Melián, S., \& Verano, D. (2008). Estilos de dirección de RRHH dentro de las empresas: Una cuestión de intensidad en la DRRHH. Cuadernos de Economía y Dirección de la Empresa, 11(36), 151-177. doi:10.1016/ S1138-5758(08)70066-5

Morales, M. (2004). Los estudios organizacionales: Un complemento para el estudio de la gestión social. Ad-administer, (21), 117-133.

Morin, E. (2005). El método V: La humanidad de la humanidad. La identidad humana. Madrid: Cátedra.

Muñoz, R. (2002). Paradigmas organizacionales y gestión humana: Por una nueva ética de la relación laboral. Revista Universidad EAFIT, 38(127), 9-17.

Ramírez, C. (1991). El método científico en el psicoanálisis. Revista Universidad de Antioquia, 6o(224), 35-41.

Ramírez, C. (2011). Apuntes. Texto policopiado por el grupo de investigación El método analítico. Medellín, 2011.

Ramírez, C. (2012). La vida como un juego existencial: Ensayitos. Medellín: Fondo Editorial Universidad EAFIT.

Rendón, M. \& Montaño, L. (2004). Las aproximaciones organizacionales. Caracterización, objeto y problemática. Contaduría y Administración, (213, 1-15.

Robbins, S. (2009). Comportamiento organizacional. México: Pearson.

Romero, R. (1998). El desarrollo del conocimiento y el manejo de las organizaciones: A propósito de la discusión sobre el taylorismo. Revista Innovar, 11, 26-38.

Rosa, A. De La, \& Contreras, J. (2007). El partido político: Entre la ciencia política y los estudios organizacionales. Investigación y análisis sociopolítico y psicosocial. México: Universidad Autónoma Metropolitana-Iztapalapa.

Rosas, J. (2006). Los estudios organizacionales: Un puente teórico entre la administración y la administración pública. Hitos de Ciencias Económico Administrativas, (34), 123-126.

Rossi, E., Mendes, A., Siqueira, M., \& García, J. (2009). Sedução e servidão em um caso de LER/DORT: Diálogo entre a pscodinâmica do trabalho e a sociología clínica. Psicología Política, 9(18), 313-330.

Saavedra, J. (2006). La administración y el origen de la concepción instrumental del hombre en la sociedad moderna. Revista Universidad y Empresa, 8(11), 237-262.

Saldarriaga, A. (2010). El sujeto activo: Antropología política en Amartya Sen. Eidos: Revista de Filosofía de la Universidad del Norte, (13), 5475 .

Zapata, A. (1995). La escuela de Montreal sobre humanismo y gestión. Cuadernos de Administración, 14(20).

Zapata, L. M. (1995). La verbalización: De la curación por la palabra al método psicoanalítico. Tesis de pregrado, Psicología, Universidad de Antioquia, Medellín. Sin publicar.

Zey, M. (1981). Criticims of the dominant perspective on organizations. The Sociological Quarterly, 22(2), 181-205. 